\title{
Performance Evaluation of a Locally Fabricated Sawdust Fired Oven for Drying Purposes
}

\author{
*EGWARE, HO; UNUAREOKPA, OJ; AWHEME O
}

\author{
Department of Mechanical Engineering, University of Benin, Benin City Nigeria \\ *Email: okechukwu.egware@uniben.edu,omozee.unuareopka@uniben.edu,oghenerobo.awheme@uniben.edu
}

\begin{abstract}
This paper evaluated the performance of a locally fabricated sawdust fired oven for drying process. The principles of energy conservation and heat recovery were applied in analyzing the data obtained from the pilot Oven. Results obtained revealed that the maximum oven temperature in the drying chamber was $130{ }^{\circ} \mathrm{C}$ after 105 minutes of the heating process. Furthermore, the maximum energy gained and efficiency computed were $3.78 \mathrm{~kW}$ and $56.65 \%$ respectively. Thus, using the sawdust fired Oven for domestic drying purpose will reduce dependence on fossil fuel; therefore, minimizing the effect of global warming and climate change. The used of the sawdust oven can serve as an alternative device for burning sawdust for drying purpose.
\end{abstract}

DOI: https://dx.doi.org/10.4314/jasem.v22i2.2

Copyright: Copyright (C) 2018 Egware et al. This is an open access article distributed under the Creative Commons Attribution License (CCL), which permits unrestricted use, distribution, and reproduction in any medium, provided the original work is properly cited

Dates: First received 12 December 2017; Received in revised form 26 January 2018; Accepted 07 February 2018

Keywords: sawdust, evaluation, energy gained, drying, oven

Human being has harnessed biomass-derived energy product since the time when people began burning of wood to make fire (Abbasi and Abbasi, 2010; Basu, 2013). Biomass is the plant and animal matter used to generate heat or electricity either by direct combustion or gasifier. It has been shown in past that over $80 \%$ of this demand is supplied by fossil fuels (Shafiee and Topal, 2009; Crutzen et al., 2016). Our dependence on electrical and thermal energy is very high, and as we utilize this energy, we are also causing stress to our environment in short term and long term. The problem with fossil fuels is that their prices are continuously fluctuating and destined to increase due to varying demand, political and economic instability, and the potential depletion of some reserves (Rout et al., 2008; González-García et al., 2013). New competitive methods of producing and using energy need to be developed and implemented to replace or reduce our dependence on fossil fuels. By using a more local and renewable energy source as a replacement, we can significantly reduce our carbon footprint and increase energy efficiency when considering the life cycle of the fuel (Bribián et al., 2011).

An oven is a thermally insulated chamber used for the heating, baking or drying of a substance, and most commonly used for cooking (McKinney, 1998). Ovens are also classified based on the fuel and energy input to power them, such gas oven, kerosene oven, fired wood oven and electric oven (Jungbluth,
1997; Arora and Jain, 2016; Oba et al., 2017). Most of the existing ovens depend on fossil fuel and electricity, which the fossil fuel and electricity used to power them are not readily available. Biomass can replace other energy resources for ovens in Nigeria (Justin, 2013); which are commonly used in the rural area because of low cost and availability (Emodi and Boo, 2015; Ali, 2016). Biomass ovens are closed containers used for heating, cooking, and drying process. It is used mostly in cooking, baking, and pottery. They provide even, dry heat to all surfaces of food inside them. In the history of biomass oven technology, different stoves/ovens have been developed and used in different part of the world such as Turkey. Traditional stoves and ovens originated from Anatolian multicultural and especially Ottoman Empire culture (Civitello, 2011). It is widely used in the rural areas where forestry products are abundant. (Klass, 1998). Sawdust stove has a similar running system as biomass stove and sawdust is used as the feedstock.

Sawdust or wood dust is a by-product of cutting, grinding, drilling, sanding, or otherwise pulverizing wood or any other material with a saw or other tool; it is composed of fine particles of woods (biomass) production (Green and Harvey 2006). Sawdust is flammable and accumulations provide a ready source of fuel. As the sawdust from which they are made is dry (on average $20 \%$ wood moisture content or less) it will burn well, leaving your stove window clear and clean with no build ups of soot (Ghafghazi et al., 
2011). It is cheap to get and renewable as well hence saw dust was chosen as the source of fuel for the oven. Research has shown that biomass (sawdust, pellets, briquettes) are much better for the environment because they emit up to $90 \%$ fewer greenhouse gases than fossil fuel (oil, coal, natural gas) (Gaspard, 2013). This makes sawdust an important consideration for the use as a fuel in the oven, which lead to the design and fabrication of a sawdust fired oven. Egware and Obanor (2013) stated that it is necessary to assess existing thermal utilities to know their performance state. The locally fabricated sawdust oven need to be investigated for its energy conversion ability. Thus, this work intends to evaluate the performance and possible utilization of saw dust oven, which can be used as an alternative device for the drying process.

\section{MATERIALS AND METHODS}

Fabrication Process of the Sawdust Fired Oven: The sawdust fired oven components were constructed from locally sourced materials and specification as shown in Table 1. The burner, drying chamber, and ash tray were constructed from mild steel sheet, which was cut to their various dimension as shown in Table 1. Thereafter, their various ends were welded with welding machine and electrodes. For the bottom of the burner was drilled 20 holes each of $20 \mathrm{~mm}$ diameter to allow for ash passage to the ash tray. Perforations were also made at the front surface of the burner to allow for air exchange.

The heat exchanger comprises tubing made of mild steel with the dimension of $70 \mathrm{~mm}$ diameter and height of $1155 \mathrm{~mm}$ after the tubing was bent and welded with welding machine and electrodes to form the frame at the heat exchanger section. The purchased steel tube is a cylindrical guide and inlet extended from the combustion chamber. The inlet protrudes vertically downwards and is in direct contact with the burning compartment to allow for heat exchange and exit of exhaust gases while the outlet is directed above the oven to the atmosphere.

The frame of the sawdust oven is made of mild steel with provision for lagging with sawdust. The mild steel material was measured with measuring tape, cut out with cutting machine and turned with a bench vice and rolling machine to the dimension as presented in Table 1. A hole was also made at the top surface of the oven frame covered with an air flap for additional heat exchange and tube exit to the atmosphere. The door hatch for the baking was measured out, cut and turned to a dimension of height $398 \mathrm{~mm}$ and thickness $50 \mathrm{~mm}$ to accommodate the saw dust lagging and afterward joined to the mild steel frame with the aid of hinges and screwed to the material. The bottom of the mild steel frame was then sealed and supports were also welded to the base. The pictorial view of the locally fabricated sawdust fired oven is shown in Figure 2.

Test and Analysis: After fabrication of the sawdust fired oven, it was tested with the cake to evaluate its performance. Sawdust was collected at the sawmill at Uselu market, Benin City at no cost. The sawdust was weighed before placing it on the burner and also, the leftover ashes. The temperatures of the oven before and after baking were measured accordingly. The time taking for the baking process was recorded. A temperature gauge is attached to the oven to give an insight into the temperature of the drying chamber which helps the individual operator to make the necessary adjustment to the sawdust loading and or burning.

The Equipment used for determining the temperature, the time taking and mass, are the thermometer, stopwatch, and scale balance. The burner was brought out of the oven and loaded with sawdust, the sawdust was burnt outside the oven for few minute to eliminate smoke in burning chamber. Then, the burner was placed back into the oven and was left for the air in drying chamber to warmed up before placing the cake into the drying chamber (preheating period). The temperature of the drying chamber was measured at $15 \mathrm{mins}$ interval till the caked was fully baked. The masses of sawdust and cake were taken accordingly. The masses flow rates of sawdust used and water loss during drying were determined by dividing the mass obtained by the corresponding time.

The assumptions made were that the effect of wind in the flame is neglected and the oven is properly lagged, which means heat loss was negligible. Considering the principle of conservation of energy on heat recovery process for drying in the sawdust oven. The performance analysis of the sawdust fired oven was carried out using Equations (1) to (3) as obtained in Egware et al. (2015), which are based on the released from the sawdust $\left(\mathrm{E}_{\mathrm{i}}\right)$, useful energy gained $\left(E_{o}\right)$ for drying process and its oven efficiency

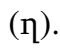

$$
E_{i}=\dot{m}_{s} C V
$$

where $\dot{m}_{s}$ the mass of sawdust and $\mathrm{CV}$ is the caloric value of sawdust.

The useful energy gained for drying process can be determined from Equation (2). 


$$
E_{o}=\dot{m}_{w} c_{p w}\left(t_{f}-t_{i}\right)
$$

where $\dot{m}_{w}$ is the mass water loss due to drying, $\mathrm{c}_{\mathrm{pw}}$ is the specific heat capacity of water as a constant pressure, $t_{f}$ is the final temperature and $t_{i}$ is initial temperature of the oven chamber.

The efficiency of the sawdust oven is calculated using Equation (3).

$$
\eta=\frac{E_{o}}{E_{i}} X 100 \%
$$

\section{RESULTS AND DISCUSSION}

Description of the Sawdust Fired Oven: The isometric and pictorial views of the locally fabricated sawdust fired oven are presented in Figures 1 and 2 respectively. The sawdust oven consists of a structural frame made of $500 \mathrm{~mm}$ square pipe of height $890 \mathrm{~mm}$ and covered with galvanized mild steel plate of $1 \mathrm{~mm}$ gauge and firmly welded to it externally and internally with proper lagging in between the internal and external sheet minimize heat loss. The frame thickness creates a void between the inner and outer galvanized metal sheet. The void is filled with an insulating material (sawdust) to prevent heat from escaping from the internal chamber to the atmosphere. The oven consists of three compartments; the upper is drying chamber, the middle is burning compartments, and lower part contain the ash tray. The drying compartment consists of two section (upper and lower drying sections) which are separated by a net-like rectangular frame (shelves). The burning compartment contains the sawdust bowl where the sawdust is loaded for onward combustion. There are perforations to allow for natural air draft to support and sustain the sawdust combustion during operation. The ashes from the burning chamber are collected in the ash tray for onward disposal.

Table 1: Material Specification of a Sawdust Fired Oven

\begin{tabular}{lllll}
\hline S/N & \multicolumn{1}{c}{ Component } & Material & \multicolumn{1}{c}{ Dimensions $(\mathbf{m m})$} & \multicolumn{1}{c}{ Quantity } \\
\hline 1 & Ash tray & Mild steel & $354 \times 358 \times 100$ & 1 \\
2 & Burner & Mild steel & $354 \times 358 \times 100$ & 1 \\
3 & Insulator & Sawdust & $\begin{array}{l}50 \text { thickness round it, } 890 \\
\text { high }\end{array}$ & - \\
& & Mild steel & $445 \times 445 \times 890$ & 1 \\
4 & Outer Shell of frame & Mild steel & $355 \times 355 \times 800$ & 1 \\
5 & Inner Shell of frame & Mild steel & $1155, \phi 70$ & 1 \\
6 & Chimney & Glass & $50 \times 338 \times 5$ & 1 \\
7 & Transparent Glass & Mild steel & $354 \times 50 \times 398$ & 1 \\
8 & Door & Mild steel & $354 \times 358 \times 400$ & 1 \\
9 & Drying Chamber & Mild steel & $358 \times 318 \times 5$ & 2 \\
10 & Rack & Mild steel & $\phi 70 \times 2$ & 1 \\
11 & Flap & & & \\
\hline
\end{tabular}

In addition to the slits on the sawdust/burning chamber, an exhaust pipe runs directly from the burning chamber through the main drying chamber for proper exhaust and heat re-use. The heat from the continuous flowing exhaust fumes is reused in the drying chamber since the heat is lost from the fumes is transfer to the drying chamber through conduction and convection modes. This heat gained in the drying chamber will help to maximize the utilization of heat release from burning sawdust. The exhaust pipe is constructed from the main chamber via an exhaust chimney which directs the extract fumes high up away to limit its adverse effect on the environment.
The sawdust and water loss during dry (parameters such as mass flow rate, Caloric Value and specific heat capacity used for the evaluation are presented in Table 2. The Caloric Value (CV) of sawdust used was obtained from Yank (2016). The test results such as time and temperature readings are presented in Table 3.

The data in Tables 2 and 3 were used to calculate the energy release rate from burning the sawdust, energy gained for drying purpose and efficiency of the fabricated sawdust fired oven as expressed in Equations (1) - (3). 


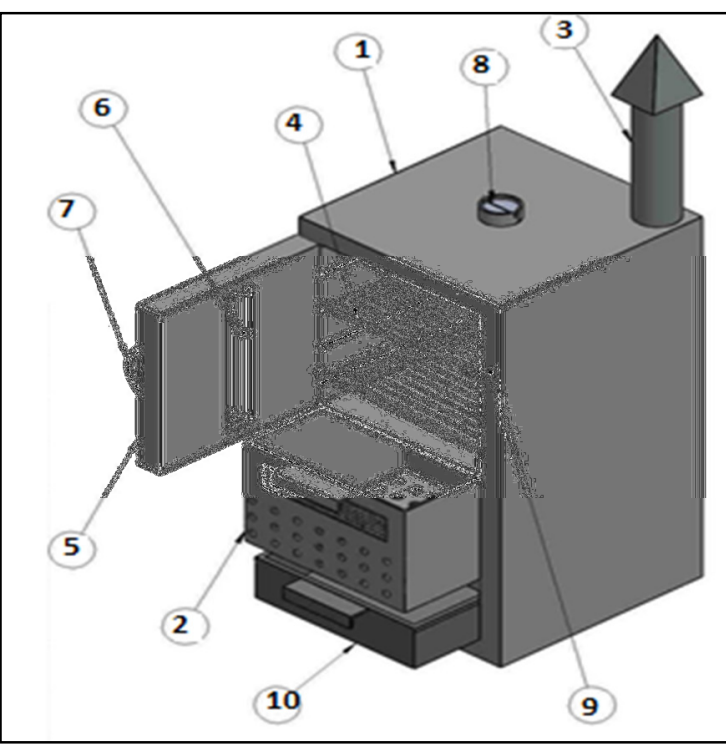

Fig 1: Isometric view of Sawdust Fired Oven: Parts: $1=$ frame; $2=$ burner $; 3=$ chimney; $4=$ shelves; $5=$ door $; 6=$ transparent glass $; 7=$ handle $; 8=$ flap $; 9=$ insulation $; 10=$ ash tray

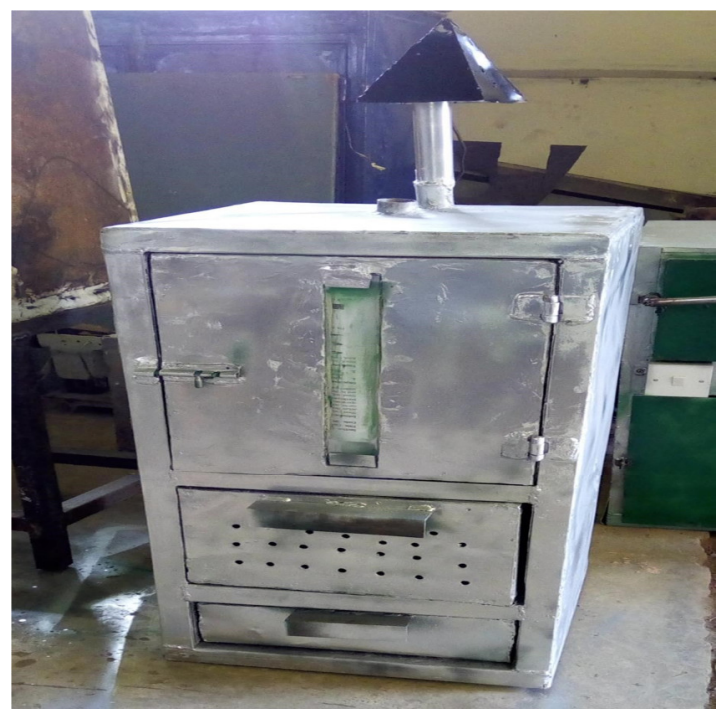

Fig 2: Pictorial view of Sawdust Fired Oven

Table 2: Dry Sawdust and Water Parameters

\begin{tabular}{lll}
\hline & Sawdust & $\begin{array}{l}\text { Water } \\
\text { loss }\end{array}$ \\
\hline Mass flow rate $(\mathrm{kg} / \mathrm{s})$ & 0.000417 & 0.009 \\
Caloric Value $(\mathrm{kJ} / \mathrm{kg})$ & 16000 & - \\
Specific heat capacity (kJ/kgK) & - & 4.2 \\
\hline
\end{tabular}

Table 3: Average Readings obtained from Sawdust Fired Oven

\begin{tabular}{llll}
\hline $\mathrm{S} / \mathrm{N}$ & Time (Minute) & $\mathrm{t}_{\mathrm{i}}\left({ }^{\circ} \mathrm{C}\right)$ & $\mathrm{t}_{\mathrm{f}}\left({ }^{0} \mathrm{C}\right)$ \\
\hline 1 & 15 & 30 & 80.0 \\
2 & 30 & 30 & 116.6 \\
3 & 45 & 30 & 121.7 \\
4 & 60 & 30 & 127.6 \\
5 & 75 & 30 & 130.0 \\
6 & 90 & 30 & 130.0 \\
7 & 105 & 30 & 127.5 \\
\hline
\end{tabular}

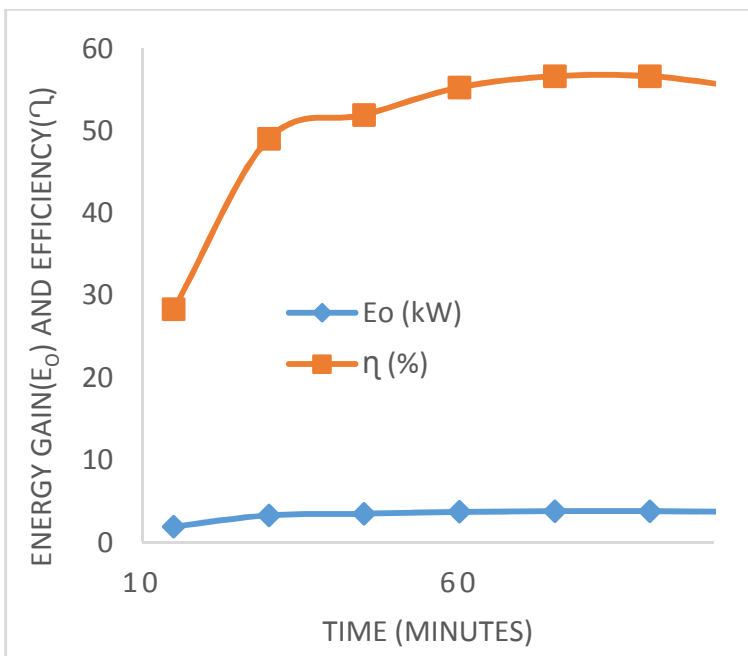

Fig 3: The Variation of Time with Energy Gain and efficiency of the Sawdust Oven

The corresponding energy gains and efficiencies of the oven for the drying process with time were presented in Figure 3. The energy release from burning sawdust was $6.672 \mathrm{~kW}$, the maximum energy gained was $3.78 \mathrm{~kW}$ and its corresponding efficiency was $55.65 \%$, which was achieved after 75 minutes of operation. The sawdust fired oven efficiency value obtained showed that more than half of the fuel energy was used for the drying process as useful energy.

The oven temperatures range obtained was 80 - 130 ${ }^{0} \mathrm{C}$, which reasonable for drying other domestic product like agricultural products and baking of the cake. The sawdust fired oven when in used will reduce the of global warming and climate change problem that would have been caused by the use of fossil fuel for the domestic drying process. This is because sawdust used as fuel is a renewable energy resource. It is another way of utilizing sawdust and it will reduce the demand for firewood, fossil fuel, and electricity for drying domestic products.

Conclusion: The performance of a locally fabricated sawdust fired oven for drying purpose was evaluated. The oven efficiency obtained revealed that more than half of fuel energy was utilized for the drying process. In addition, the oven temperatures range make it suitable for drying domestic like agricultural products and baking process. The use of sawdust fired oven for domestic drying process will reduce fossil fuel and electricity consumption, it will also help to make cleaner environment by minimizing sawdust waste in the surrounding. 


\section{REFERENCES}

Abbasi, T; Abbasi, SA (2010). Biomass energy and the environmental impacts associated with its production and utilization. Renewable and Sustainable Energy Reviews, 14(3): 919-937.

Ali, AM (2016). Energy Consumption Patterns in Urban and Peri-urban Households of ArbaMinch town, Southwestern Ethiopia (Doctoral dissertation, Addis Ababa University)

Arora, P; Jain, S (2016). A review of chronological development in cook stove assessment methods: Challenges and way forward. Renewable and Sustainable Energy Reviews, 55:203-220.

Basu, P (2013). Biomass gasification, pyrolysis and torrefaction: practical design and theory. Academic press

Bribián, IZ; Capilla, AV; Usón, AA (2011). Life cycle assessment of building materials: Comparative analysis of energy and environmental impacts and evaluation of the eco-efficiency improvement potential. Building and Environment, 46(5) :1133-1140.

Civitello, L (2011). Cuisine and culture: A history of food and people. John Wiley \& Sons.

Crutzen, PJ; Mosier, A R; Smith, KA; Winiwarter, W (2016). $\quad \mathrm{N}_{2} \mathrm{O}$ release from agro-biofuel production negates global warming reduction by replacing fossil fuels. In Paul J. Crutzen: a pioneer on atmospheric chemistry and climate change in the Anthropocene (pp. 227-238). Springer International Publishing.

Egware, HO; Obanor, AI (2013). Energy Analysis of Omotosho Phase I Gas Thermal Power Plant, Inter. J. Engineer. Technol. Sci. 1 (4): 206 - 207.

Egware, HO; Osaze, O; Enoma, N (2015), Performance Evaluation of a Domestic Solid Waste Incinerator Water Heater, $J$. Multidisciplinary Sci. Technol. Vol. 2, Issue 5: 1090 - 1093.

Emodi, NV; Boo, K J (2015). Sustainable energy development in Nigeria: Current status and policy options. Renewable and Sustainable Energy Reviews, 51: 356-381

Gaspard, S; Mohamed, CN (2013). Biomass for Sustainable Applications: pollution remediation and energy, 18th edition, RSC Green Chemistry Publisher, Harvard.
Ghafghazi, S; Sowlati, T; Sokhansanj, S; Bi, X; Melin, S (2011). Particulate matter emissions from combustion of wood in district heating applications. Renewable and Sustainable Energy Reviews, 15(6):3019-3028

Green, D; Harvey, L (2006) wood: craft, culture, history penguin books, New York, page 403.

González-García, S; García-Rey, D; Hospido, A (2013). Environmental life cycle assessment for rapeseed-derived biodiesel. Inter. J.Life Cycle Assess. 18(1): 61-76.

Jungbluth, N (1997). Life-cycle-assessment for stoves and ovens. ETH, Eidgenössische Technische Hochschule Zürich.

Justin, DO (2013). Wood fibre plants generate violations. Wall street journal, biomass conversion to useful energy, Vol. 112:1-1566.

Klass, DL (1998). Biomass for renewable energy, fuels and chemicals, San Diego Academic

McKinney, EF (1998). U.S. Patent No. 5,786,568. Washington, DC: U.S. Patent and Trademark Office.

Oba, OE; Ejivwie, PO; Akhator, EO; Isesele, PK (2017). Design and Fabrication of a Sawdust Fired Oven, B.Eng Thesis, Department of Mechanical Engineering, University of Benin, Benin City, Nigeria.

Rout, UK; Akimoto, K; Sano, F; Oda, J; Homma, T; Tomoda, T (2008). Impact assessment of the increase in fossil fuel prices on the global energy system, with and without $\mathrm{CO}_{2}$ concentration stabilization. Energy Policy, 36(9): 3477-3484.

Shafiee, S; Topal, E (2009). When will fossil fuel reserves be diminished? Energy policy, 37(1): 181-189.

Yank, A; Ngadi, M; Kok, R (2016). Physical properties of rice husk and bran briquettes under low pressure densification for rural applications. Biomass Bioenergy. 84: 22-30. 